\title{
Effect of Rigid Links Young's Modulus on Turbo- Generator Foundation FE Dynamic Analysis
}

\author{
${ }^{1}$ Mohamed Khaled, ${ }^{2}$ Shady Gomaa \\ ${ }^{1}$ M.Sc. Graduate Student, Structural Engineering Dept., Faculty of Engineering, Helwan University, Cairo, Egypt \\ ${ }^{2}$ M.Sc. Holder, Structural Engineering Dept., Faculty of Engineering, Ain Shams University, Cairo, Egypt
}

\begin{abstract}
Turbo Generator foundation is one of the Paramount structures; if not the most one; in power generation plants. For the Turbo Generator foundation design, finite element (FE) is the commonly acknowledged analysis tool in structural engineering field. As the turbine and generator are relatively rigid compared either to the foundation or to the soil in analysis, both machines contributes in the finite element model through their masses applied at their center of gravity. Those elevated masses are connected to the foundation using rigid links / rigid beam elements in order to transfer loads / masses from the machines CG level to the foundation level. Rigid links are usually simulated in the analysis model as beam elements with a large Young's modulus value relative to other elements presented in the model (e.g., 100 times stiffer than the elements they are linked to) [1]. The aim of this paper is to examine study and recommend the most efficient rigid links Young's modulus value and modeling method in order to simulate the actual behavior of the system to reach the optimum dynamic and static analysis results of the Turbo Generator foundation. the analysis result indicates that using Young's modulus for the rigid link equal to ten-thousand-time steel young's modulus provide the most realistic dynamic behavior for the machine foundation.
\end{abstract}

Keywords: Rigid links, Young's modulus, Dynamic analysis, Turbo Generator, Static analysis, foundation.

\section{INTRODUCTION}

Free vibration dynamic responses of turbo-generator foundation due to own weight and equipment masses, same as other systems responses, depend on the characteristics of damping and stiffness. Each system has a unique dynamic response nature whether it is transient, periodic, or random. Such responses lead to a considerable effect on vibration, cracking, and settlement of machine foundations. Excessive uncontrolled vibrations may lead to malfunction of rotating machines operation especially if amplitudes amplification due to resonance occurred. Such a phenomenon causes severe damages to both machines and facility; moreover, it affects the safety of the workers within the vicinity. To predict and control the actual behavior and vibration of the turbogenerator foundation system, simulating the presence of the machines accurately is of a considerable effect; this is made up of means of elevated frame elements simulating the rotor elevation of the machines with respect to foundation surface. As axial movements of the rotor only act at the bearing casing connection point of the combined radial/axial bearing (thrust bearing), so this rotor (elevated frame element) is linked to the relevant anchoring point on the foundation by means of several rigid links. The characteristic of those rigid links is to be very stiff but without defined mass. For this reason, it is commonly considered for these links a material with the same characteristics of the concrete with a density equal to zero and geometrical characteristics (inertia and area) quite large. The first order natural frequencies and each harmonic (i.e. higherorder natural frequencies) having significant mass participation shall be evaluated. The corresponding displacements and velocities at steady state or at startup and shut down shall be monitored in order to keep the structure low tuned far enough away from the normal operating speed to prevent dynamic excitations from its surroundings.

This study aims to examine, evaluate, and recommend the most appropriate rigid links geometrical characteristics; modulus of elasticity; which effectively simulates and predicts the actual free vibration responses of the turbo-generator foundation system.

\section{MODELING}

The structural modeling to assess the effect of the rigid link on the turbine foundation is performed using a tabletop foundation comprises of a fixed base, set of columns, and top deck slab with the required opening. Foundation geometry is shown in figure (1). The tabletop foundation structure is analyzed by finite element analysis using sap2000 version (21) software. Deck slab is modeled using Shell (Thick) elements which include the effect of transverse shear deformation. Reinforced concrete columns frame elements.

\subsection{Model data}

Concrete Compressive stress Fc' $40 \mathrm{MPa}$

Mass density of concrete 


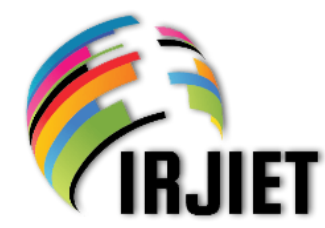

Concrete Elastic Modulus Ec

$35670.48 \mathrm{MPa}$

Steel Elastic Modulus Es

Top Deck dimension

Top Deck elevation

Turbine CG elevation $199947.98 \mathrm{MPa}$

$33.8 \mathrm{~m} \times 12.8 \mathrm{~m}$

$+14.00 \mathrm{~m}$

$+14.76 \mathrm{~m}$

\subsection{Turbine masses}

$\begin{array}{ll}\text { HIP turbine } & 37000 \mathrm{Kg} \\ \text { LP turbine } & 81000 \mathrm{Kg} \\ \text { Generator } & 56000 \mathrm{Kg}\end{array}$

\subsection{Global Axes in sap Model}

Z Vertical direction, $\mathrm{X}$ and $\mathrm{Y}$ Horizontal directions.
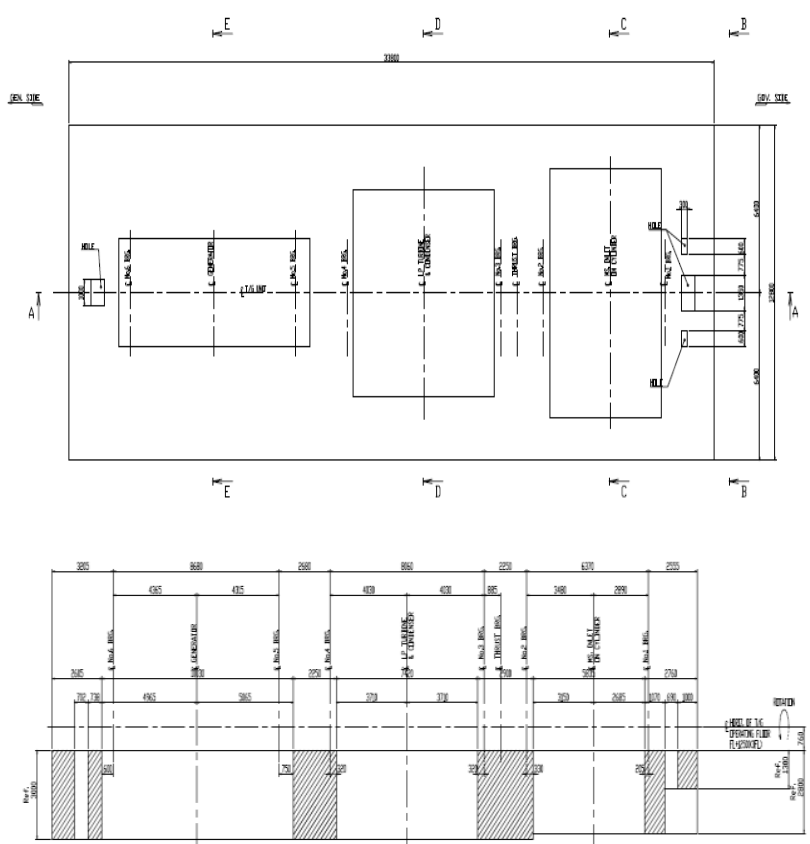

Figure 1: Turbine pedestal, Top deck dimensions

Machine lumped masses are modeled using three different methods and all these methods will be compared to one control model.

\subsection{Method 1}

This method consists of five models which the machine lumped masses are modeled at its masses center (CG) and connected to the top deck slab using Rigid Links. Rigid links are modeled using a weightless frame element, for this method a set of models are performed with different rigid links young's modulus to configure the most optimum one that reflects the real dynamic behavior of the foundation in comparison with the control model as shown in figure (2).

- First model (M1): rigid link young's modulus equal to steel. E $199947.98 \mathrm{MPa}$

ISSN (online): 2581-3048

Volume 5, Issue 10, pp 40-44, October-2021 https://doi.org/10.47001/IRJIET/2021.510008

- Second model (M10): rigid link young's modulus equal to 10 times. E $1999479.8 \mathrm{MPa}$.

- Third model (M100): rigid link young's modulus equal to 100 times. $\mathrm{E}=19994798 \mathrm{MPa}$

- Fourth model (M1000): rigid link young's modulus equal to 1000 times. $\mathrm{E}=199947980 \mathrm{MPa}$.

- Fifth model (M1000): rigid link young's modulus equal to 10000 times. $\mathrm{E}=1999479800 \mathrm{MPa}$.

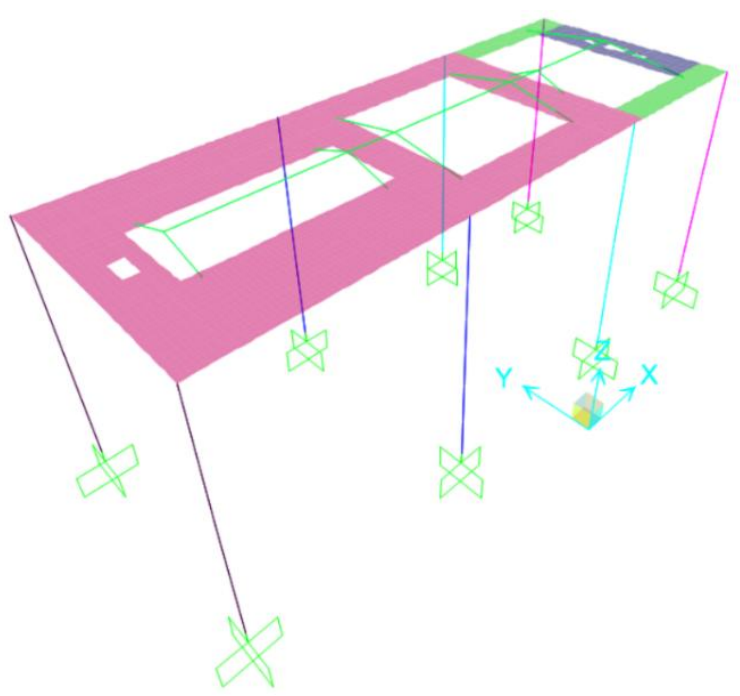

Figure 2: Method (2) Finite element Model using rigid links

\subsection{Method 2}

The machine lumped masses are modeled at its masses center (CG) and connected to the top deck slab using a built-in Rigid Links facility in sap 2000 software. Options for this link is chosen to be weightless and fixed for all transition and rotation movements. Model for this method is tagged as (ML) and the dynamic behavior of the foundation in comparison with the control model as shown in figure (3).

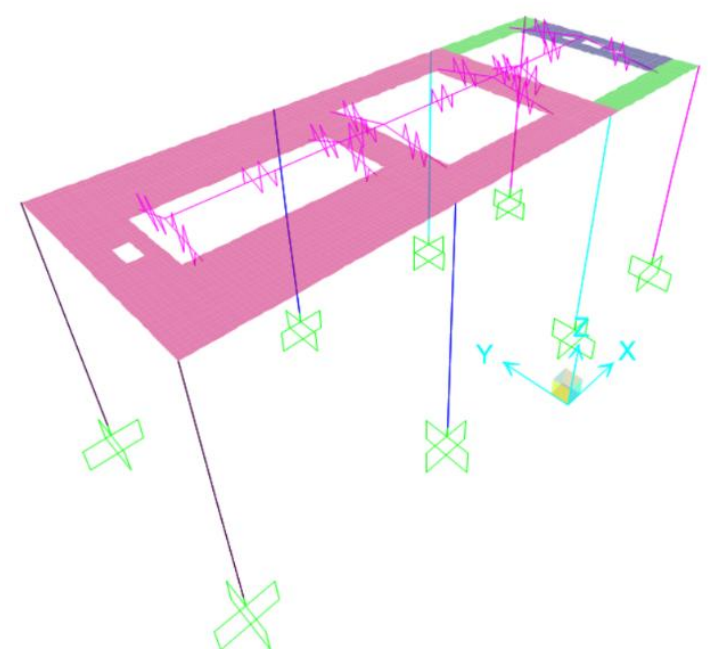

Figure 3: Method (2) Finite element Model Rigid Links facility in sap 2000 software 
ISSN (online): 2581-3048

Volume 5, Issue 10, pp 40-44, October-2021 https://doi.org/10.47001/IRJIET/2021.510008

\subsection{Method 3}

The machine lumped masses are modeled at its masses center (CG) and connected to the top deck slab using Body Constraint facility in sap 2000 software. Model for this method is tagged as (MR) and the dynamic behavior of the foundation in comparison with the control model as shown in figure (4).

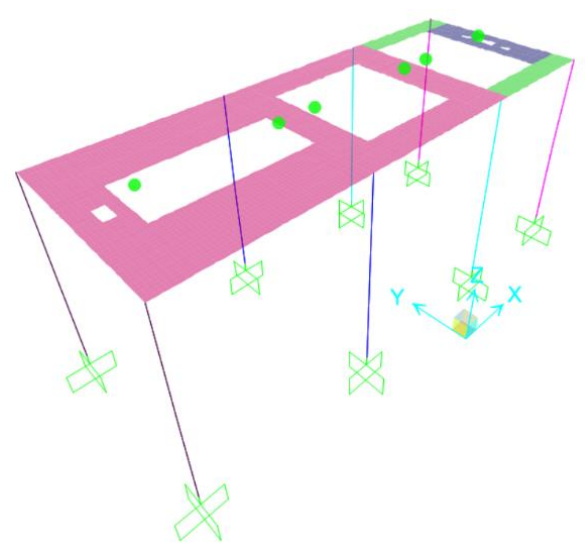

Figure 4: Method (3) Finite element Model Rigid Links facility in sap 2000 software

\subsection{Control model}

The control model (MC) includes no rigid links or elevated masses to ensure that the model is represent the real dynamic behavior for the foundation. The elevated machine masses are simulated in the (MC) by transferring them from the machine elevated $\mathrm{CG}$ to corresponding forces and moments applied directly at the deck slab joints level considering the difference in height between the elevated CG and the deck slab. In order to reach the optimum simulation of the system behavior when using the rigid links method instead of the (MC) approach, different values of rigid links young's modulus is examined as shown in figure (5).

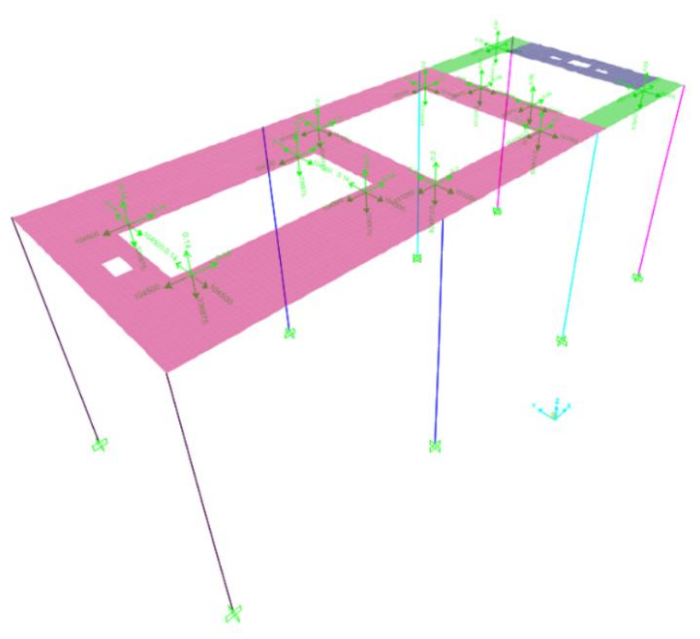

Figure 5: Finite element Model (MC) no rigid links are used

\section{RESULTS AND DISCUSSIONS}

Fundamental frequency and corresponding mass participation ratios are investigated for each model in order to achieve the most effective modeling concept to simulate the actual dynamic behavior as shown in tables (1) to (8). For (MC), the fundamental frequency is (3.11) HZ with $86.60 \%$ MPR in (Y) direction. For (M1), fundamental frequency is (0.38) HZ with $30.00 \%$ MPR in (X) direction. For (M10), the fundamental frequency is (1.19) $\mathrm{HZ}$ with a $36.00 \% \mathrm{MRP}$ in (X) direction. For (M100), fundamental frequency is (2.74) HZ with $84.00 \%$ MPR in (X) direction. For (M1000), fundamental frequency is (3.11) HZ with $89.00 \%$ MPR in (Y) direction. For (M10000), fundamental frequency is (3.11) HZ with $90.00 \%$ MPR in (Y) direction. For (MR), the fundamental frequency is (2.96) HZ with $91.00 \%$ MPR in (Y) direction. For (ML), fundamental frequency is (2.96) HZ with $91.00 \%$ MPR in (Y) direction. Natural frequencies Comparison between the control model (MC) and all other models to study which method of analysis will reflect the real dynamic behavior are shown in figures (6) to (13).

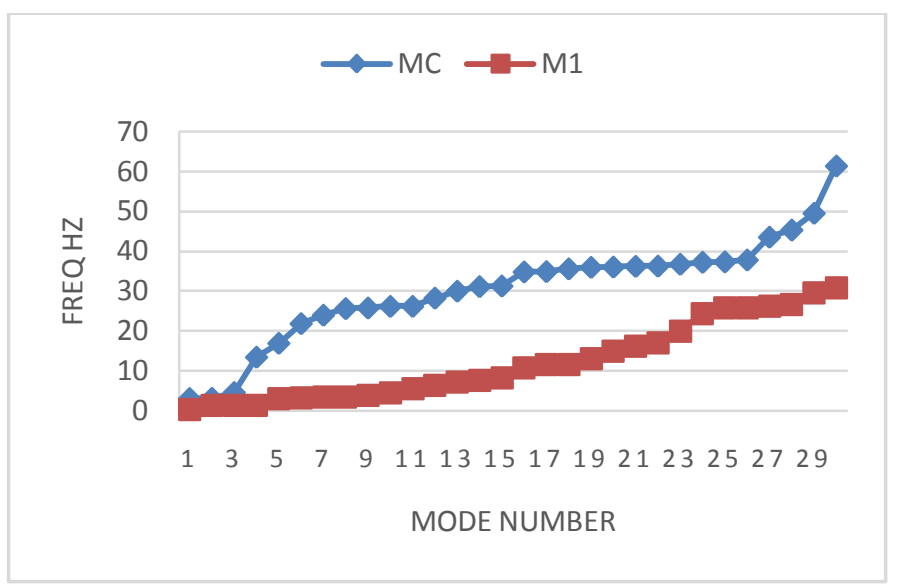

Figure 6: Natural frequencies Comparison between model MC and model M1

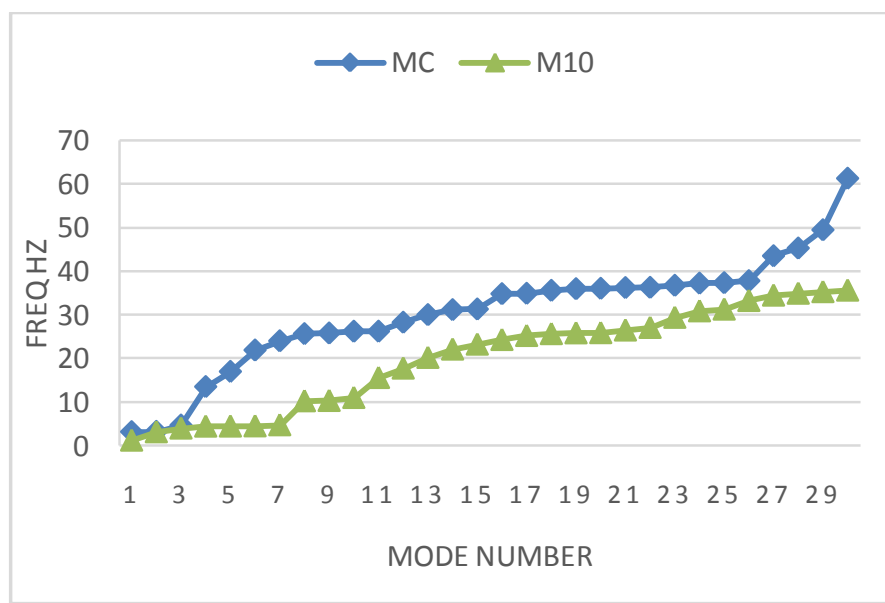

Figure 7: Natural frequencies Comparison between model MC and model M10 
ISSN (online): 2581-3048

IRJIET

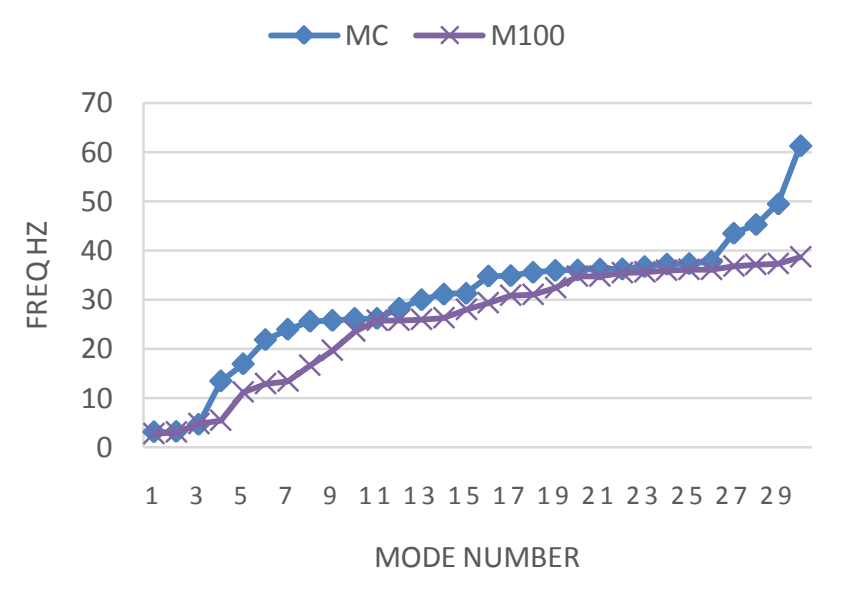

Figure 8: Natural frequencies Comparison between model MC and model $\mathbf{M 1 0 0}$

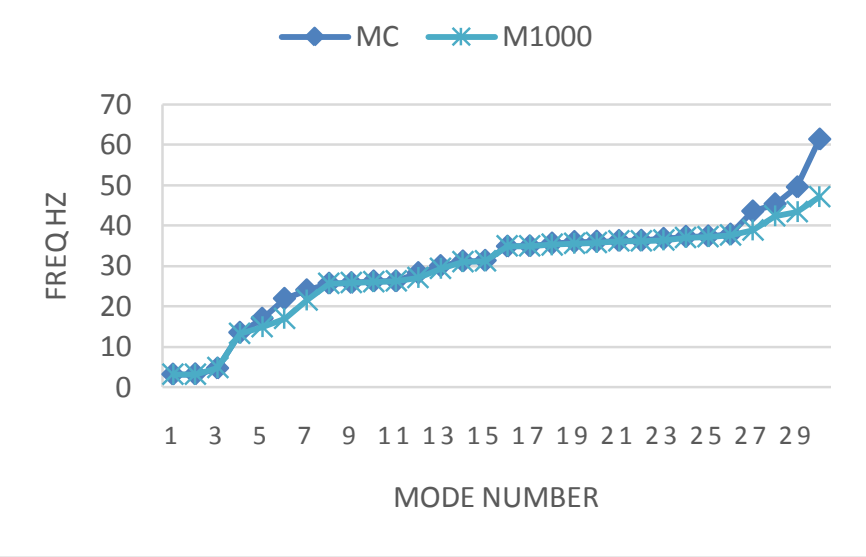

Figure 9: Natural frequencies Comparison between model MC and model M1000

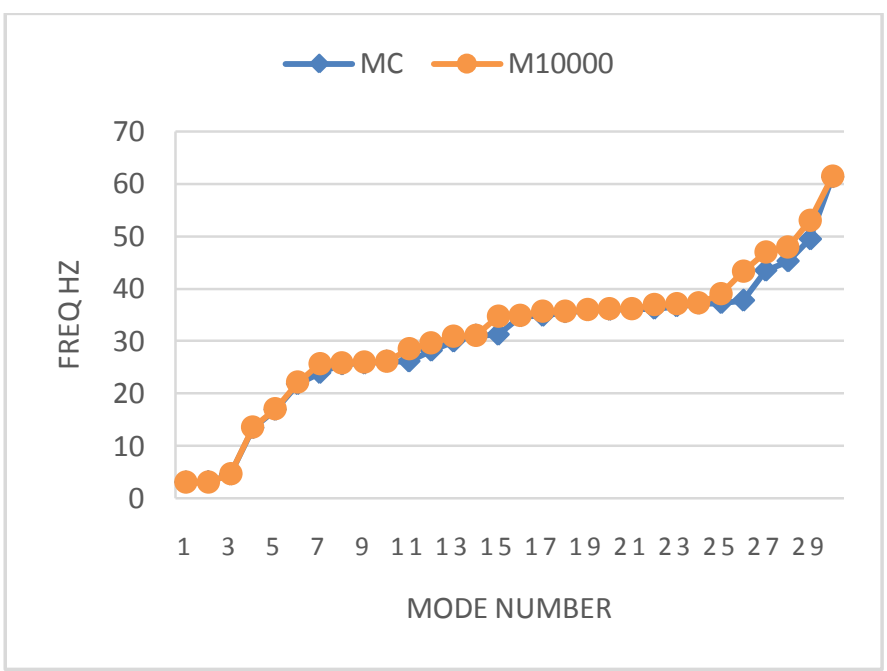

Figure 10: Natural frequencies Comparison between model MC and model M10000
Volume 5, Issue 10, pp 40-44, October-2021 https://doi.org/10.47001/IRJIET/2021.510008

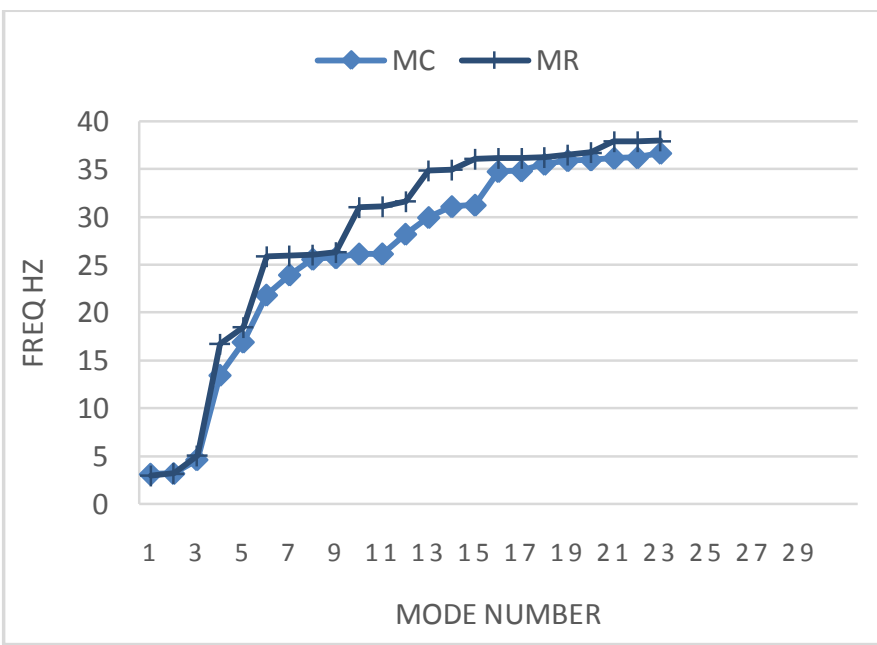

Figure 11: Natural frequencies Comparison between model MC and model MR

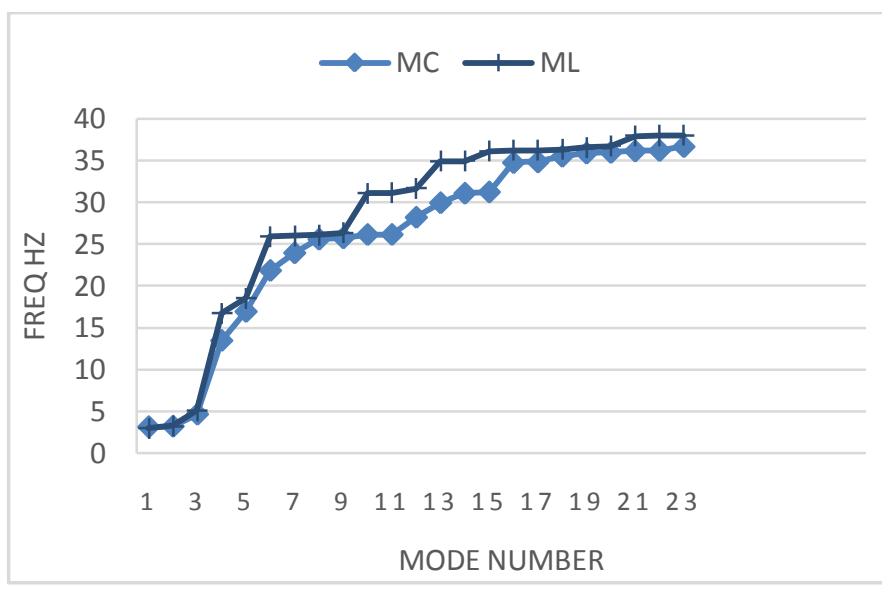

Figure 12: Natural frequencies Comparison between model MC and model ML

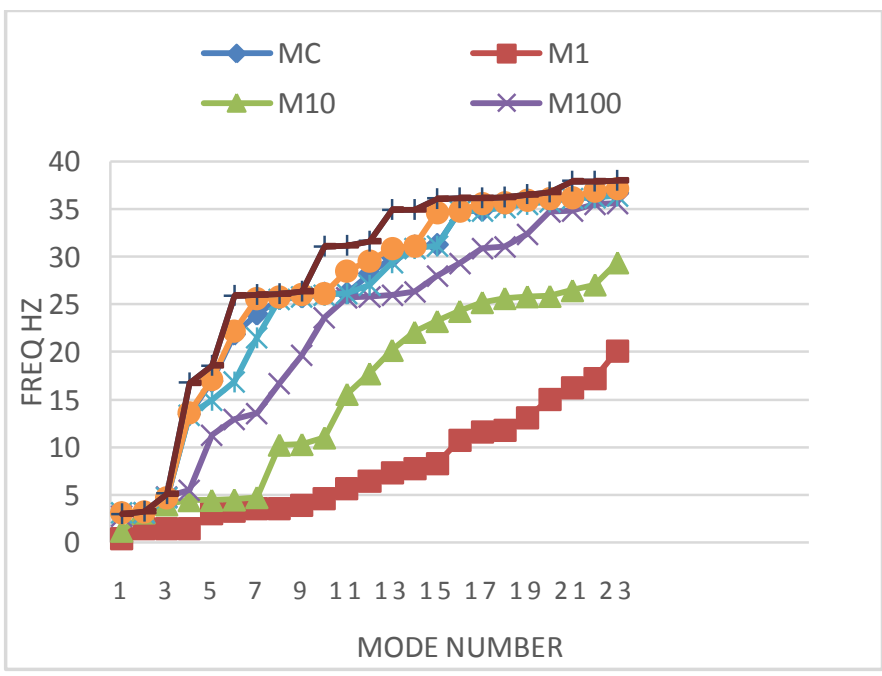

Figure 13: Natural frequencies Comparison between All modeling methods 
ISSN (online): 2581-3048

Volume 5, Issue 10, pp 40-44, October-2021

https://doi.org/10.47001/IRJIET/2021.510008

\section{CONCLUSION}

For the Finite Element method (FEM) dynamic analysis of machine foundation, using rigid links to connect elevated lumped masses of machines to the foundation is considered an efficient simulation tool. Rigid links properties need attention to assure reflecting the real dynamic behavior of the system. The paper investigated and studied various methods for values for rigid link young's modulus; the conclusion of the study is summarized below:

- Using young's modulus for Rigid link equal (10,000) times the steel young's modulus reflects the real dynamic behavior for the machine foundation system and it's the most recommended method for rigid link properties modeling.

- SAP 2000 built-in Rigid Links and Body constraint modeling options reflect the real dynamic behavior for the machine foundation system.

- Using young's modulus for Rigid link equal (10) or (100) times the steel young's modulus doesn't reflect the real dynamic behavior for the machine foundation and it's not recommended to be used for rigid link modeling.

\section{REFERENCES}

[1] ASCE. "Concrete Foundations for Turbine Generators". ASCE Manuals and Reports on Engineering Practice No. 136, May, 2018.

[2] K.G Bhatia, "Foundation for Industrial Machines" handbook for practice engineers. First edition, 2008.

[3] Jayarajan P., Kouzer K.M, Dynamic analysis of turbogenerator machine foundationsl, Journal of Civil Engineering and Environmental Technology, Volume 1, Number 4; August, 2014, pp. 30 - 35.

[4] K Vijaya Kumar, Static and modal analysis of steam turbine base frame International Journal of Advance
Research in Science and Engineering, IJARSE, Vol. No.4, Issue No.02, February 2015.

[5] SungyaniTripathy, A.K Desai, Dynamic analysis of turbo generator frame foundation using SAP: $2000 \mathrm{v}$ 17.1 software, 50th Indian Geotechnical Conference, 2015.

[6] ArkadyLivshits, Dynamic analysis and structural design of Turbine generator foundations, European built environment $\mathrm{CAE}$ conference.

[7] Vlad, Ion. "Mathematical Modelling and Experimental Dynamic Investigation of an Elevated Foundation Supporting Vibration Machinery." (2001).

[8] Peter Nawrotzki, Gunter Huffmann and Timur Uzunoglu, Static and Dynamic analysis of concrete turbine foundations, Structural Engineering International, Volume 18, Number 3, August 2008, pp. 265-270.

[9] SAP2000 v14, Structural Analysis Program, Computers andStructures Inc., Berkeley, California. www.csiberkeley.com

\section{AUTHORS BIOGRAPHY}

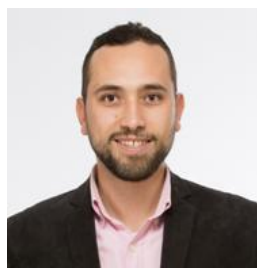

Mohamed Khaled, Post graduate student, Department of Civil and structural Engineering at Helwan University, Egypt. Voting member of ACI committee 351 (Equipment Foundation).

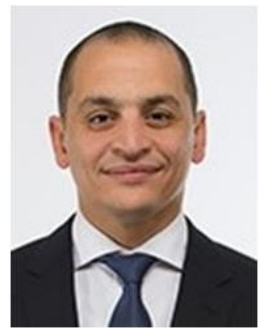

Shady Gomaa, Master's degree holder from Department of Civil and structural Engineering at Ain shams university, Egypt. Voting member of ACI committee 351 (Equipment Foundation).

\section{Citation of this Article:}

Mohamed Khaled, Shady Gomaa, "Effect of Rigid Links Young's Modulus on Turbo-Generator Foundation FE Dynamic Analysis" Published in International Research Journal of Innovations in Engineering and Technology - IRJIET, Volume 5, Issue 10, pp 40-44, October 2021. Article DOI https://doi.org/10.47001/IRJIET/2021.510008 